\title{
The Impact of Okun Misery Index on Out-of-pocket- payments in the Iranian Healthcare System
}

\section{Aziz Rezapour}

Iran University of Medical Sciences

Salar Ghorbani ( $\nabla$ salar.ghorbany66@yahoo.com )

iran university of medical sciences

Eisavi Mahmoud

allameh tabatabaei university

Saeed Bagheri Faradonbeh

iran univesity of medical sciences

\section{Research}

Keywords: Okun Misery Index, Out-of-pocket-payments, Healthcare System

Posted Date: November 9th, 2020

DOI: https://doi.org/10.21203/rs.3.rs-100948/v1

License: (c) (1) This work is licensed under a Creative Commons Attribution 4.0 International License.

Read Full License 


\title{
The Impact of Okun Misery Index on Out-of-pocket-payments in the Iranian Healthcare System
}

Aziz Rezapour $^{1}$, Salar Ghorbani ${ }^{2}$, Eisavi Mahmoud ${ }^{3}$, Saeed Bagheri Faradonbeh ${ }^{4}$

1- Associate Professor, Health Management and Economics Research Center, Iran University of Medical Sciences, Tehran, Iran

2- PhD student in Health Economics, School of Health Management and Information Sciences, Iran University of Medical Sciences, Tehran, Iran

3- Faculty of Economics, Allameh Tabatabai University, Tehran, Iran

4- Ph.D. of Health Economics, Health Management and Economics Research Center, Iran University of Medical Sciences, Tehran, Iran

\begin{abstract}
Introduction: One criterion to measure the achievement of a government's performance is stability and decreasing the misery index that is the sum of inflation and unemployment. Therefore, this study aims to investigate the impact of misery index on patients' out-of-pocket-payments in the Iranian healthcare system.
\end{abstract}

Methods: This paper has used time-series data from 2000 to 2016 and it used three methods to examine the relationship between variables. First, the Dickey-Fuller test was used to evaluate the stationary of variables. Second, the Toda-Yamamoto causality test was used to test causality between variables. Third, Auto-Regressive Distributed Lags (ARDL) was used to test the long-run relationship. Analyzing data was conducted by Eviews 9 software.

Results: The results showed that there was a bi-directional causal relationship between the misery index and the out-of-pocket-payments of patients in the health system. Also, increasing 1 unit of misery index increased 1.33 units of out-of-pocket-payments. The correction error coefficient was 0.435 that meant this amount was adjusted per period. In other words, it lasted more than 2 years and less than 3 years that the Nonequilibrium points converge to their long-run points of the relationship.

Conclusion: Implementing appropriate policies in order to reduce unemployment and inflation rate can decline the out-of-pocket-payments in the Iranian healthcare system.

Key words: Okun Misery Index, Out-of-pocket-payments, Healthcare System 


\section{Introduction}

One of the most important challenges in developing countries is the high and growing costs of public health services. Poverty and debt are increasing because of out of pocket costs in a way that families pay a major part of health services cost (1). A large share of out-of-pocketpayments can prevent a country to reach the fair financing $(2,3)$. Catastrophic health expenditure which is defined as one characteristic of out-of-pocket-payments consists of $\% 10$ of the total annual household income or $\% 40$ of the food expenses of annual household income. Out-of-pocket-payments is an amount paid by the individual to receive healthcare services(4). Estimates from household surveys globally show 100 million people become poor annually and 150 million people face severe economic problems due to the direct healthcare expenditure which $\% 90$ of them live in low-income countries (5). Patients in lowincome and middle-income countries that haven't any kind insurance coverage have to pay costs by out of pocket so it put them below the poverty line. In addition, they lose the opportunity to earn money during illness. In fact, the negative effect of out-of-pocketpayments is higher than for the poorer people $(6,7)$. Financial catastrophe or severe economic problems can occur in all countries at all level of income but catastrophic health expenditure varies in different groups, for example, the poor, illiterate, people without insurance coverage, rural households, women heads of households, and families with a member suffering from chronic illness are affected very high respect to other groups(8). The healthcare costs are high for different age groups but it is much higher for older people and they have more worries about them $(8,9)$. The Healthcare system is comprehensive when it can provide services with high quality and support patients financially. Although the former mostly occurs, the later isn't seen mostly (10).

Economists used many indicators to analyze the welfare situation. One of these indicators is the misery index that the changes of it directly affect the welfare situation so it is a criterion to measuring of success of governments. Also reducing and stability of it are required to the stability of the governments $(11,12)$. The misery index is considered as a measure to the welfare situation(13) and it is introduced for the first time by Arthur Okan in the 1970s. Okan presented the sum of Unemployment and inflation rates as misery index with this assume that increasing these rates imposes the economic and social costs (14).

\section{Okan Misery Index = Unemployment Rate + Inflation Rate}

Generally, low misery index recognized as a sign of economic stability. According to the experience of developed countries as a standard rule, one country will in favorable economic conditions if the misery index is lower than $\% 7$. Of course, the amount of $\% 10$ is tolerable but the amount higher than $\% 10$ usually shows the significant problems in the economic system $(15,16)$. A high misery index in a country infers to the severe economic and social problems of people in a society. In fact, increasing the misery index has a negative effect on economic growth because it decreases the demand for consumer goods and services and it leads to economic recession $(17,18)$. According to the World Bank, Iran's economy is among the top ten countries in terms of the high inflation rate with \%10 inflation rate in 2017 (19). Also according to International Labor Institution, the unemployment rate in Iran has been \%12.1 that compared with Middle East countries and the world has far distance to the 
desirable condition (19). According to the World Bank, Iran doesn't have a proper condition in terms of out-of-pocket-payments among other countries. The rate of out-of-pocketpayments is \%38.8 that has a decreasing trend after 2013 due to implementing health sector evolution plan that government allocated more budget to the health sector. The maximum rate has been \%60 and \%59.4 in 2000 and 2010 respectively (19). The subject of this study is novel and the basis of the author's searching wasn't found any paper with the same subject. Therefore, considering the importance of misery index, out-of-pocket-payments, and the existing research gap in this field, the researchers decided to examine the impact of these two variables on the Iranian health system in this study.

\section{Methodology}

This paper is an applied research that was divided into the descriptive and the analytical methods. In the descriptive part, the documentary and library method has been used and the analytical part was based on the three econometric methods. First, the Dickey-Fuller test was used to evaluate the unit root of data. Second, The Toda-Yamamoto causality test was used to test causality between variables. Third, Auto-Regressive Distributed Lags (ARDL) was used to test the long-run relationship. Analyzing data was conducted by Eviews 9 software. This study was conducted in 2020 and based on data from 2016 to 2000.

\section{- Dickey Fuller Stationary Test}

One series such as $y_{t}$ is stationary at first difference means $y_{t} \sim I(1)$ even if it has unit root at level. In other words, If $y_{t}$ is non-stationary, $\Delta y_{t}$ will stationary if $\Delta y_{t}=y_{t}-y_{t-1}$ is stationary. Based on before statement, $y_{t}$ is stationary series at difference $d$. it means that $y_{t} \sim I(d)$ or $\Delta^{d} y_{t}$. Practically, Dickey Fuller test evaluate the existence of unit root in three categories consist of with intercept, with trend, and with trend and intercept. It considers the below regression model:

$$
\Delta \mathrm{y}_{\mathrm{t}}=\mathrm{c}+\beta \mathrm{t}+\delta \mathrm{y}_{\mathrm{t}-1}+\sum \gamma_{\mathrm{i}} \Delta \mathrm{y}_{\mathrm{t}-\mathrm{i}}+\varepsilon_{\mathrm{t}}
$$

Where $\mathrm{P}$ is the number of lags that tests the condition of white noise of residuals, $\mathrm{c}$ is the intecept, $\mathrm{t}$ is the trend, and $\Delta$ is the difference symbol. It is important to emphasize that the reason of unpredictable of a stochastic trend is the time dependency between residuals' variance. If $\beta$ and $\delta$ coefficients equal to zero, then the series can be analyzed basis on a stochastic process. The null hypothesis is to have unit root and it is rejected when the $t$ statistic is higher than critical values $(20,21)$.

\section{- Toda-Yamamoto Causality Test}

Toda and Yamamoto (1995) proposed a simple method in the way of estimation of an adjusted VAR. they suggested that this method is valid even when there is a cointegrated relationship between variables. In this method, first, the optimum lags $(\mathrm{k})$ of the model should be determined. Then, the maximum of cointegrated degree (dmax) is specified. Finally, the model is formed on the basis of the number of lags $(k+d m a x)$. Of course, the 
process of selection lag is valid when $\mathrm{k}+\mathrm{dmax} \leq \mathrm{k}$. therefore, if we consider the two-variable model, Toda-Yamamoto Test is as the following:

$$
\begin{aligned}
& \mathrm{X}_{\mathrm{t}}=\omega+\sum_{i=1}^{m} \theta \mathrm{i} \mathrm{Xt}-\mathrm{i}+\sum_{i=m+1}^{m+d \max } \theta \mathrm{i} \mathrm{Xt}-\mathrm{i}+\sum_{i=1}^{m} \sigma \mathrm{iYt}-\mathrm{i}+\sum_{i=m+1}^{m+d m a x} \sigma \mathrm{iYt}-\mathrm{i}+\mathrm{v}_{1} \\
& \mathrm{Y}_{\mathrm{t}}=\Psi+\sum_{i=1}^{m} \phi \mathrm{iYt}-\mathrm{i}+\sum_{i=m+1}^{m+d m a x} \phi \mathrm{iYt}-\mathrm{i}+\sum_{i=1}^{m} \beta \mathrm{i} \mathrm{Xt}-\mathrm{i}+\sum_{i=m+1}^{m+d m a x} \beta \mathrm{i} \mathrm{Xt}-\mathrm{i}+\mathrm{v}_{2 \mathrm{t}}
\end{aligned}
$$

Wald statistic is used in the test that has a chi-square distribution with freedom degree without constraints and the constraint Wald test is run on the main lags of $\mathrm{k}(22)$.

- Auto-Regressive Distributed Lags (ARDL)

When the variables of regression are cointegrated at first difference or higher, it is necessary to test the existence of a long-term relationship. In this study, auto-regressive distributed lags (ARDL) method was used to investigate the long-term relationship and estimate the equations that are based on the t-test. One of the good features of this method is the use of both zero and one cointegrated. This method not only estimates the long-term relationships between variables but also can estimate the dynamic and short-term relationships. Also, this method estimates the coefficient of adjustment that shows the required periods to reach equilibrium in terms of the long-run relationship. Finally, it has better and more efficient results in small samples $(23,24)$.

In the ARDL method, the following equation was estimated:

$\mathrm{y}_{\mathrm{it}}=\sum_{j=1}^{p} \lambda \mathrm{ijyi}, \mathrm{t}-\mathrm{j}+\sum_{j=0}^{q} \sigma \mathrm{ijxi}, \mathrm{t}-\mathrm{j}+\Upsilon i d i+\varepsilon i t$

Where $\mathrm{y}_{\mathrm{t}-\mathrm{j}}$ is the dependent variable with lag $\mathrm{i}, \mathrm{x}_{\mathrm{t}-\mathrm{j}}$ is an independent variable with lag $\mathrm{i}, \mathrm{d}_{\mathrm{i}}$ is the vector of independent variables without lag. One important feature of ARDL method is that estimating of above equation considers the dynamic of short-run, consequently, the estimation is without bias. After estimating of above equation, the existence of long-run relationship between variables are tested. If the sum of the dependent variable's coefficients $\left(\lambda_{\mathbf{i}}\right)$ is less than 1 , it can be stated that there is a long-run relationship between variables. This test is conducted by the following method:

$$
\mathrm{H}_{0}=\sum_{j=0}^{P} \lambda \mathbf{j}-\mathbf{1}=\mathbf{0} \quad \mathrm{H}_{1}=\sum_{j=0}^{P} \lambda \mathbf{j}-\mathbf{1}<\mathbf{0} \quad \mathrm{t}=\frac{\sum_{j=1}^{p} \lambda \mathbf{j}-\mathbf{1}}{\sum_{j=1}^{p} S E \lambda \mathbf{j}}
$$

The null hypothesis is rejected when the t statistic is higher than the critical value in table. After confirming the existence of the long-run relationship and without spurious regression, the long-run equation as the following:

$$
\begin{aligned}
& \mathrm{Y}_{\mathrm{t}}=\left(\frac{\sum_{j=1}^{q} \sigma j}{1-\sum_{j=1}^{p} \lambda \mathrm{j}}\right) \mathrm{x}_{\mathrm{t}}+\left(\frac{r}{1-\sum_{j=1}^{p} \lambda \mathrm{j}}\right) \mathrm{W}_{\mathrm{t}}+\varepsilon_{\mathrm{t}} \\
& \mathrm{Y}_{\mathrm{t}}=\sigma_{\mathrm{j}} \mathrm{X}_{\mathrm{t}}+\Upsilon^{\mathrm{L}} \mathrm{W}_{\mathrm{t}}+\varepsilon_{\mathrm{t}}
\end{aligned}
$$

Finally, the error term and the error correction equation are as the following:

(Error correction equation) $\mathrm{ECM}_{\mathrm{t}}=\mathrm{y}_{\mathrm{t}}-\sigma_{\mathrm{t}}^{\mathrm{L}} \mathrm{x}_{\mathrm{t}}+\Upsilon^{\mathrm{L}} \mathrm{w}_{\mathrm{t}}$ 
(Error term) $\Delta \mathrm{y}_{\mathrm{t}}=\mu \Delta \mathrm{x}_{\mathrm{t}}+\lambda \Delta \mathrm{w}_{\mathrm{t}}+\theta \mathrm{ECM}_{\mathrm{t}-1}+\varepsilon_{\mathrm{t}}$

In the error term equation, the ECMt-1 coefficient is called the error correction coefficient, which indicates the adjustment velocity towards the long-term equilibrium. The error correction coefficient must be between zero and negative 1. It means that each period decrease as amount as error correction coefficient from the non-equilibrium, and after a while the non-equilibrium is removed and the short-term and long-term coefficients become the same (23-25).

\section{Results}

- Stationary Test Estimation

In order to be able to estimate the Toda-Yamamoto method, we need to have the stationary rank of the variables and the optimal lag, so we first tested the stationary of the variables using the augmented Dickie-Fuller test. As shown in Table (1) all variables were nonstationary and at the level and they were stationary at the first difference, so both variables and methods were cointegrated in rank 1.

Table (1): Dickey-Fuller Test Results

\begin{tabular}{|c|c|c|c|c|c|c|}
\hline variable & \multicolumn{2}{|c|}{$\begin{array}{c}\text { Critical Values of the } \\
\text { McKinnon Test }\end{array}$} & Value & $\begin{array}{c}\text { Confidence- } \\
\text { level }\end{array}$ & P-Value & Result \\
\cline { 2 - 7 } & $\begin{array}{c}\text { Without } \\
\text { intercept } \\
\text { and trend }\end{array}$ & $\begin{array}{c}\text { With } \\
\text { intercept } \\
\text { and trend }\end{array}$ & & & & \\
\hline Misery index & -2.42 & 2.31 & -2.42 & 10 & 0.15 & Non-stationary \\
\hline Out of pocket & -0.15 & 0.30 & -0.15 & 10 & 0.95 & Non-stationary \\
\hline Misery index(-1) & 3.95 & 1.37 & 3.95 & 10 & 0.01 & Stationary \\
\hline Out of pocket (-1) & -2.83 & -1.17 & -2.83 & 10 & 0.07 & Stationary \\
\hline
\end{tabular}

Source: Research Findings

As can be seen from Tabel 1, the misery index variable was non-stationary at level and this variable has been stationary at first difference, as well as, the result for out of pocket was the same. The condition for using the Toda-Yamamoto causality test is that the variables should be stationary at first difference. As the results showed that all the variables had the aforementioned condition, so it is possible to use the Toda-Yamamoto causality test.

- Toda-Yamamoto Causality Test

It is not necessary to know the features of the cointegration of the model in the TodaYamamoto causality test. The results of Wald-test and the significance level of coefficients with optimal lag were presented in Tabel 2. As shown in Table 2, there is a bi-directional causality relationship between the misery index and out-of-pocket payments in the health system. 
Table 2, Wald Test Results

\begin{tabular}{|c|c|c|c|c|}
\hline $\begin{array}{c}\text { Dependent } \\
\text { variable }\end{array}$ & Effective Variable & Wald Statistic $\mathbf{X}^{\mathbf{2}}$ & Prob & Result \\
\hline Misery Index & Out of Pocket & 223.08 & 0.000 & Confirmed \\
\hline Out of Pocket & Misery Index & 223.08 & 0.000 & Confirmed \\
\hline
\end{tabular}

Source: Research Findings

Since the probability of chi-square statistic was less than $\% 1$, therefore, the null hypothesis of existence of non-causality was rejected, and the misery index was the causality of out of the pocket payment. Also, the probability of chi-square statistics was less than $\% 1$, so the null hypothesis was rejected.

Table 3 ARDL Bounds Test

\begin{tabular}{|c|c|c|}
\hline \multicolumn{2}{|c|}{ Test Statistic } & \multicolumn{2}{c|}{ Value } \\
\hline \multicolumn{2}{|c|}{ F-statistic } & \multicolumn{2}{c|}{} \\
\hline \multicolumn{3}{|c|}{ Critical Value Bounds } \\
\hline Significance & I0 Bound & I1 Bound \\
\hline$\% 10$ & 3.02 & $\mathbf{3 . 5 1}$ \\
\hline$\% 5$ & 3.62 & $\mathbf{4 . 1 6}$ \\
\hline$\% 2.5$ & 4.18 & $\mathbf{4 . 7 9}$ \\
\hline $\mathrm{R}^{2}=0.76$ & 4.94 & $\mathbf{5 . 5 8}$ \\
\hline
\end{tabular}

ARDL method consists of three parts, dynamic equation, long-term equation, and error correction. The dynamic equation is based on the auto-regressive model that its results presented in Table 3. As can be seen from Tabel 3, the statistic $\mathrm{F}$ was estimated 3.799 which was greater than the short-term value at the level of $\% 10$. So, the estimation model was statistically significant at confidence interval $\% 90$ and the dynamics of the model were confirmed. Also, the estimated model had a coefficient of determination with $\% 76$, which meant that $\% 76$ changes of the dependent variables were explained by the independent variable.

Table 4, ARDL Cointegrating and Long Run Form

\begin{tabular}{|c|c|c|c|c|}
\hline \multicolumn{5}{|c|}{ Cointegrating Form } \\
\hline Variable & coefficient & Std. Error & t-statistic & prob \\
\hline cointEq(-1) & -0.435 & 0.219 & -1.983 & $\mathbf{0 . 0 8 7}$ \\
\hline \multicolumn{4}{|c|}{ Long Run Coefficients } \\
\hline Variable & coefficient & Std. Error & t-statistic & prob \\
\hline Misery index & 1.33 & 0.635 & 2.10 & $\mathbf{0 . 0 7 3}$ \\
\hline C & 91.54 & 17.84 & 5.13 & $\mathbf{0 . 0 0 1}$ \\
\hline
\end{tabular}

Source: Research Findings

The long-term coefficients that were estimated by ARDL method have been presented in Table 4 . The results showed that the variables were statistically significant at \%10 level. Misery Index had a 
positive effect on out-of-pocket-payments during the long run in the Iranian health system. According to results, increasing 1 unit of misery index increased out-of-pocket-payments 1.33 units on average.

The error correction coefficient is the most important part of the error correction model (ECM) which shows the rate of adjustment of the non-equilibrium process. The estimated coefficient was negative and statistically significant so it was valid. As can be seen in Table 4, the estimated coefficient was 0.435 , which meant that -0.435 of each period was adjusted from the short-term non-equilibrium to reach the long-term equilibrium. In other words, it lasted more than two years and less than three years for short-term non-equlibrium to cointegrate to their long-term equilibrium relationship.

\section{- Discussion}

The main purpose of this study was to investigate the effect of misery index on out-of-pocket payment in the Iranian health system, using auto-regressive distributed lags, during the period 2000 to 2016. For this purpose, after conducting stationary tests for variables, Toda-Yamamoto causality test was tested to investigate the existence of causality between the misery index and the out-of-pocket payments in the Iranian health system. The result of causality test showed that there was a bidirectional causal relationship between two variables. Then, ARDL method was used to estimate the dynamic, long-term, and error correction models. The dynamic model was confirmed and the estimated long-term coefficients showed that the variables were statistically significant at level of $\% 10$ as well as the effect of misery index was direct and positive on the out-of-pocket-payments in the Iranian health system in a way that one unit in increasing the misery index increased 1.33 unit to the out-of-pocket-payments. The estimated coefficient of error correction model (ECM), which shows the rate of nonequilibrium adjustment, was -0.435 which meant each period as amount as -0.435 of the short-run nonequilibrium was adjusted to reach long-term equilibrium.

According to studies, given that low-income countries are unable to meet health expenditures through domestic sources to meet the goals of the World Health Organization, they need foreign assistance. With the inflow of large amounts of foreign currency into these countries, if there is no proper management and efficiency, it may have a negative impact on exports and economic growth, leading to an increase in inflation in these countries. This can not only lead to an economic phenomenon called "Dutch disease", but also increase the misery index (26-28). So we can say that the relationship between the misery index and the amount of out-of-pocket payments and health expenses can be a cycle and each has a direct impact on the other and this cycle is repeated, which is consistent with our study. Also, according to a research, the results of estimating the Durbin spatial model have been the effect of the misery index on health expenditures and the amount of out-of-pocket payments(29), which is consistent with our study. Kazemian et al. concluded that increasing income and reducing inflation have a positive effect on health expenditures and out-of-pocket payments, and an increase in the unemployment rate has a negative effect on health expenditures and out-of-pocket payments (30). According to the study of $\mathrm{Wu}$ et al., The misery index has a direct effect on the growth and continuity of people's health expenses and the amount of out-of-pocket payments (31). Therefore, the positive and significant effect of the misery index on the amount of out-of-pocket payments and their health expenditures shows the importance of this index in the field of health. Given the importance of health in the development of human capital, it is necessary for the government to reduce the inequality of health expenditures. It is also necessary to make policy in the health system in such a way that the priority of financing is a combination of different methods and with the priority of reducing the share of households in direct payment when receiving health services.

Health is a multidimensional commodity that can affect the economic, social, and political dimensions of societies. Lack of use and get access to health goods and services by members of society can cause major problems(32). The high rate of out-of-pocket payments is a very important factor that can limit 
patients' access to health goods and services. The increase in the misery index, which is the result of total inflation and unemployment, is another obstacle in accessing and using people's health care services because increasing this index in two dimensions can affect the rate of access. First, increasing the misery index, the income of families decreases that causes a decline in purchasing power for health goods and services. Second, increasing the misery index leads to higher out-of-pocket payments (increasing 1 unit in the misery index increases out of pocket by 1.33 units). Also, when the payment increases from the patients' pocket, patients have less ability to access healthcare services.

Therefore, the healthcare system should strengthen itself in order to provide comprehensive services and reduce the burden of healthcare costs(33). Although increasing access to health care services in less developed countries is important, Families must also be protected from the negative consequences of out-of-pocket payments (34).

The high amount of out-of-pocket-payments leads to poverty for vulnerable groups in the Iranian health system. The Iranian health system must take basic steps to reduce out-of-pocket payments. In recent years, various projects have been implemented by this system that the most important one is the Iranian Health System Transformation Plan which has resulted in decreasing out-of-pocket payments in 2010 from $59 \%$ to $38 \%$ in 2016.

Bagheri et al. Found that $2.4 \%$ of all households and $3.9 \%$ of households that used health services fell below the poverty line due to out-of-pocket payments for health care services. Out-of-pocket payments for health care in this study were equal to $2.4 \%$ (35). In 2003, Wagstaff et al. Examined health care payments and health care-related poverty in Vietnam during 1993 and 1998. The difference between the poor population before and after the payment of health expenses was estimated at about 3.5 percent. Although the difference between the pre-payment and post-payment poverty gaps was about 1 percent, in 1993 the difference between the pre-payment poor population and the post-payment poor population was 4.4 percent (36).

\section{- Conclusion}

According to the obtained results from the model estimation, the misery index had a positive and statistically significant effect on the out-of-pocket payment in the Iranian health system. The high level of out-of-pocket payments in the healthcare system is rooted in the country's economic problems. Iran's economy is an economy dependent on oil. also, government ownership in various sectors of the economy is high, and when oil prices rise and the oil economy is booming, government revenues increase and more funds are allocated to the health sector that leads to recline out-of-pocket payments and vice versa. The government should allocate a stable fund to finance health sector by developing social insurance and taxation on goods and services by negative effects that they can reduce the out-of-pocket-payments.

Finally, based on the main results of this study, the government should take primary measures to reduce the misery index. Since the misery index is composed of total inflation and unemployment, government policies should be applied to reduce these two variables. In recent decades, Iran's economy has structural and fundamental problems and it has suffered from double-digit inflation and unemployment rates. The government should implement targeted plans to decrease inflation such as increasing competitiveness of the economy, reducing the size of administration, monetary and financial discipline, preventing print of money without backing. Also, in order to reduce the unemployment rate, it should consider efforts such as the real privatization, industrial renewal, reduction of the current budget, reduction of administrative bureaucracy, prevention of government rents, and provision of facilities to the production sector in relation to other unnecessary sectors of the 
economy that these factors cause to reduce of misery index and subsequently lead to decrease in the out-of-pocket-payments.

\section{- References}

1. Mishra S, Mohanty SK. Out-of-pocket expenditure and distress financing on institutional delivery in India. International journal for equity in health. 2019;18(1):99.

2. Organization WH. Obesity: preventing and managing the global epidemic: World Health Organization; 2000.

3. Rezapour A, EBADIFARD AA, Asadi S, BAGHERIFARADONBEH S, Toofan F. ESTIMATING THE ODD-RATIO OF FACTORS AFFECTING HOUSEHOLDS'EXPOSURE TO CATASTROPHIC AND IMPOVERISHING HEALTH EXPENDITURES. 2016.

4. Yap A, Cheung M, Kakembo N, Kisa P, Muzira A, Sekabira J, et al. From procedure to poverty: out-of-pocket and catastrophic expenditure for pediatric surgery in Uganda. journal of surgical research. 2018;232:484-91.

5. Xu K, Evans DB, Carrin G, Aguilar-Rivera AM, Musgrove P, Evans T. Protecting households from catastrophic health spending. Health affairs. 2007;26(4):972-83.

6. Bijlmakers L, Wientjes M, Mwapasa G, Cornelissen D, Borgstein E, Broekhuizen H, et al. Outof-pocket payments and catastrophic household expenditure to access essential surgery in Malawi-A cross-sectional patient survey. Annals of Medicine and Surgery. 2019;43:85-90.

7. Rezapour A, Arabloo J, Movahed MS, Faradonbeh SB, Alipour S, Alipour V. Catastrophic Health Expenditure and Impoverishment Among Households with Cardiovascular Patients in Tehran, 2017. Shiraz E-Medical Journal. 2019;21(1).

8. Pandey A, Ploubidis GB, Clarke L, Dandona L. Trends in catastrophic health expenditure in India: 1993 to 2014. Bulletin of the World Health Organization. 2018;96(1):18.

9. Kumara AS, Samaratunge R. Patterns and determinants of out-of-pocket health care expenditure in Sri Lanka: evidence from household surveys. Health policy and planning. 2016;31(8):970-83.

10. Business WEs. Strengthening Health Systems to Improve Health Outcomes: WHO's Framework for Action. Geneva: WHO. 2007.

11. Cavanaugh KL, King KD, editors. Simultaneous transfer function analysis of Okun's misery index: Improvements in the economic quality of life through Maharishi's Vedic Science and technology of consciousness. Proceedings of the American Statistical Association, Business and Economics Statistics Section; 1988.

12. Lovell MC, Tien P-L. Economic discomfort and consumer sentiment. Eastern Economic Journal. 2000;26(1):1-8.

13. Barro R. Macroeconomics: A modern approach: Cengage Learning; 2007.

14. Tang $\mathrm{CF}$, Lean $\mathrm{HH}$. New evidence from the misery index in the crime function. Economics Letters. 2009;102(2):112-5.

15. Dadgar Y, Rahmani T. Principles of economics. Tehran: Boostan Publisher; 2011.

16. Dadgar $Y$, Nazari R. The impact of economic growth and good governance on misery index in Iranian economy. European Journal of Law and Economics. 2018;45(1):175-93.

17. Okun A. The Political Economy of Prosperity-Brookings Institution, Washington D. 1970.

18. Okun AM. Prices and quantities: A macroeconomic analysis (Brookings Institution, Washington, DC). C; 1981.

19. Bank W. World Bank country and lending groups. World Bank Data Help Desk Washington (DC); 2017.

20. Dogan E. Foreign direct investment and economic growth: a time series analysis of Turkey, 1979-2011. Journal of the Faculty of Economics and Administrative Sciences. 2013;3(2):239-52. 
21. Cheung Y-W, Lai KS. Lag order and critical values of the augmented Dickey-Fuller test. Journal of Business \& Economic Statistics. 1995;13(3):277-80.

22. Alimi SR, Ofonyelu CC. Toda-Yamamoto causality test between money market interest rate and expected inflation: the Fisher hypothesis revisited. European Scientific Journal. 2013;9(7).

23. Pesaran $\mathrm{MH}$, Shin $\mathrm{Y}$, Smith RP. Pooled mean group estimation of dynamic heterogeneous panels. Journal of the american statistical association. 1999;94(446):621-34.

24. Frimpong Magnus J, Oteng-Abayie EF. Bounds testing approach: an examination of foreign direct investment, trade, and growth relationships. American Journal of Applied Sciences, Forthcoming. 2006.

25. Kim Kh. Dollar exchange rate and stock price: evidence from multivariate cointegration and error correction model. Review of Financial economics. 2003;12(3):301-13.

26. Wang Z, Rettenmaier AJ. A note on cointegration of health expenditures and income. Health economics. 2007;16(6):559-78.

27. Murthy VN, Okunade AA. The core determinants of health expenditure in the African context: Some econometric evidence for policy. Health policy. 2009;91(1):57-62.

28. Beheshti M, Sojoudi S. The relationship between health expenditure and GDP in Iran. 2008.

29. Rezaei $H$, Alizadeh $M$, Nademi Y. Examining the spatial spillover effects of misery index on health care expenditure in selected developing countries. 2017.

30. Kazemiyan M, Javadi-Nasab H. Socio-economic Determinants of Health Expenditure for Lowincome Householdsin the Informal Sector. Journal of Kerman University of Medical Sciences. 2014;21(2):151-61.

31. Wu P-C, Liu S-Y, Pan S-C. Does misery index matter for the persistence of health spending? Evidence from OECD countries. Social indicators research. 2014;118(2):893-910.

32. Eisavi M, Ghorbani S, Moiedfar A, Holakoupour M. Wagner's Law Test on Health Expenditure in Iran. Iranian Journal of Health Insurance. 2019;2(3):134-41.

33. Buigut S, Ettarh R, Amendah DD. Catastrophic health expenditure and its determinants in Kenya slum communities. International journal for equity in health. 2015;14(1):46.

34. Saksena $\mathrm{P}, \mathrm{Xu} \mathrm{K}$, Durairaj V. The drivers of catastrophic expenditure: outpatient services, hospitalization or medicines. World health report. 2010;1:21.

35. Faradonb S, Arab M, Roodbari M, Rezapoor A, Faradonbeh H, Azar F. Catastrophic and impoverishing health expenditure in Tehran urban population. Journal of Health Administration (JHA). 2016;19(63).

36. Wagstaff A, Doorslaer Ev. Catastrophe and impoverishment in paying for health care: with applications to Vietnam 1993-1998. Health economics. 2003;12(11):921-33. 